\title{
ФИЛОСОФИЯ И ПОЛИТИКА: ОПЫТ СООТНЕСЕНИЯ МЕТОДОЛОГИЙ НА ПРИМЕРЕ ДИАЛОГА АЛЕКСАНДРА КОЖЕВА И ЛЕО ШТРАУСА
}

\begin{abstract}
Аннотация: Статья посвященаметодологическим проблемам полититических наук. На примереполемики Лео Штрауса и Александра Кожева продемонстрированы основные приемы работы современных исследователей, указаны их слабые места, дан анализ причин и намечены наиболее перспективные варианты решения. В качестве ориентира указан путь, пройденный науками об экономике. Политология, очевидно, в силуотносительно недавней своей институциализации, все еще пользуется языком философии из-за чего ее результаты часто выглядят архаичныли на фоне достижений других гуманитарных наук. Недостаточное привлечение к сотрудничеству математики, нейронаук, статистики и проч. сказывается на уроне знаний и даже на некотором их застое. Средний трактат о власти, написанный в начале двадиать первого века, за редким исключением ничем не отличается от трактата, увидевщего свет два, три и даже четыре века назад. Эзотерическая и философская тенденции подвергнуты критике, как пагубные итормозящие дальнейшее развитие. Review: The article is devoted to the methodological problems of political sciences. Based on an example of the polemics between Leo Strauss and Alexander Kozhev, the author shows the key working methods of modern researchers, and their weak spots. The author also provides analysis of the causes of the problems and potentially productive options for their resolution. The author takes the development of economic sciences as a reference point. The political science has been institutionalized only recently, and it still uses the philosophical vocabulary, that is why its achievements sound archaic compared to achievements of other humanities. The lacking involvement of mathematics, neurosciences, statistics, etc. causes loss and stagnation of knowledge. The typical thesis on power written in the early XXI century rarely differs from the theses, which appeared two to four centuries ago. Esoteric and philosophic tendencies are being criticized as harmful and thwarting further progress. Ключевые слова: литература, критика, статистика, знание, разитие науки, методология, власть, философия, политика, междисииплинарные исследования
\end{abstract}

Keywords: literature, criticism, statistics, knowledge, cognition, development of science, methodology, power, philosophy, politics, interdisciplinary studies.

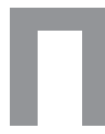

олитология, как и ее ближайшие родственницы, социология и экономика, как и вообще любая гуманитарная дисциплина, от рафинированного литературоведения до брутальной этологии, постоянно сталкивается с проблемой истинности своих выводов. Как бы она ни старалась, даже сейчас, после стольких открытий и прорывов, достоверность полученного знания и признание оного соответствующим научным критериям, остается, по меньшей мере, проблематичным. Отсюда вытекает особое отношение к старым гипотезам: если в естественных науках, например, в физике, они сменяют друг друга с головокружительной скоростью и, сменяясь, за редким исключением, уходят в архив навсегда, у гуманитариев им приходится терпеть друг с другом невероятно долго. Замечания о природе политического, сделанные в эпоху античности, столь же ценны, как и самые современные, опирающиеся на новейшие методики. Более того, у античных авторов есть преимущество респектабельности, некий шарм, никак не связанный с логическим и фактическим подтверждением. Как будто мысль, записанная на древнем пергаменте или на толстой гуттенберговской бумаге, обладает большим весом, по сравнению с записанной на электронном носителе. Романтическое отношение к потертым фолиантам так бы и осталось романтическим, возвышенным настроением и эстетической эмоцией, если бы политологии удалось обрести твердую почву под ногами. Та же экономика, изначально будучи простым наблюдением за товарно- 
DOI: $10.7256 / 1811-9018.2013 .10 .9567$

При цитировании этой статьи сноска на доі обязательна

Правовая и политическая мысль

денежным оборотом, написанным в жанре философического трактата, в наше время из всех сил стремится оставить в прошлом конструкции восемнадцатого века с тем, чтобы в ближайшем будущем стяжать попперианские добродетели. Нейроэкономика предлагает строить модель поведения человека на основании экспериментов, проведенных в лабораторных условиях. В случае удачи, можно будет заменить писательскую проницательность c ее непостоянством и слепыми пятнами, графиками мозговой активности ${ }^{1}$. Эконометрика делает ставку на работу со статистическими данными, что опять же, снимает необходимость во врожденном таланте, замещая его математическими моделями и цифрами, всегда прозрачными и всегда проверяемыми. Историческая экономика, в отличие от предыдущих двух, как будто сохраняет связь с гуманитаристикой, на самом деле использует приемы анализа, заимствованные из современной исторической науки. Одинокий автор, полагающийся только на свой опыт и в нем одном черпающий вдохновение, и тут оттеснен на периферию. Нечто подобное, с поправкой на специфику, в скором будущем должно произойти и с политологией. Статистика, нейронауки, документально подтвержденная генеалогия институтов или что-то другое, доселе нам не неизвестное, отделят публицистику и литературу от, собственно, знания. До тех пор ученые, специализирующиеся на изучении феноменов власти, вынуждены использовать технический арсенал чуть ли не античности, как, к слову сказать, и философы. Последним, правда, простительно, ибо их задачи слишком размыты, а предмет невероятно огромен. Описывая реальность, всю без остатка, какая она есть “на самом деле”, они вынуждены, иногда, вопреки желанию, уходить в сферу искусства, беря на вооружение язык высокой поэзии, о чем красноречиво свидетельствуют трактаты Хайдеггера ${ }^{2}$. Политологи, когда отказываются следовать физикам, тоже склоняются к творчеству. Для словесности это может быть и хорошо, однако, сравнивая философию, страдающую от необъятности темы, с политологией, проблематика которой, в общем, обозрима и прозрачна, нетрудно заметить излишний пессимизм последней. Описываемая материя туманна, используемый язык не совершенен, но не настолько, чтобы отказываться от достижений научного прогресса и возвращаться во времена Сократа и Платона. Было бы странным,

\footnotetext{
${ }^{1}$ Философия экономики. Антология / Под ред. Дэниела Хаусмана. M. 2012.

${ }^{2}$ Хороший разбор темы у Steven B. Smith Reading Leo Strauss: politics, philosophy Judaism Chicago 2006 C. 110- 129.
}

живя в материальном окружении постиндустриального мегаполиса, пользоваться идеями, созданными на заре исторической эпохи, хотя, надо заметить, здесь и сейчас именно так и происходит.

В этом отношении полемика между Лео Штраусом и Александром Кожевым ${ }^{3}$ по поводу истинного значения трактата Ксенофонта является эталонной. Ее техническое оснащение настолько архаично, настолько лишено связи с современностью, ее выводы, при всей помпезности их предъявления, настолько обычны, как будто за последние две с половиной тысячи лет ничего не произошло. И тот и другой заняты текстовым анализом, суть которого - соотнесение личного опыта участия в политической игре с мыслью Ксенофонта. Естественно, они не соглашаются друг с другом, что впрочем, нормально, учитывая допущенную степень субъективности. С обеих сторон ссылаются на случаи из собственной практики, на что любой методолог ответит градом критических замечаний. Неужели они действительно верили в возможность сойтись во мнениях? Неужели политическая реальность настолько унифицирована? Сугубо личный опыт Кожева, при всем уважении к его проницательности, уму и эрудиции, не является последней инстанцией, равно как и опыт Штрауса, человека, несомненно, выдающегося. Политическая материя коснулась их, в этом легко убедиться, сопоставив биографии, весьма серьезно, оба они находились, что называется, в гуще событий, и, тем не менее, нет гарантии совпадения. Опыт Кожева и опыт Штрауса не равны друг другу, как неравны опыты двух разных людей. Даже если бы они каким-то чудом оказались абсолютно идентичны, что уже невероятно, разница интеллектуального багажа непременно бы дала о себе знать. Словом, два наблюдателя, при всем, повторимся еще раз для верности, пиетете к их заслугам в области гуманитарных наук, - это недостаточно ни для какой индукции. Защищая обратное, можно было бы указать на литературу, освоенную ими. Штраус, равно как его и оппонент, знаком с теориями прошлого, но методика анализа, применяемая ими обоими, не дает ничего нового. Они идут по протоптанной дороге гуманитарного рассуждения, увлекаются феноменологией и метафорами, настойчиво игнорируя возможности естественных наук. Ни математики, ни биологии, ни статистики. Предложи они результаты опросов, результаты обработки биографических данных, ре-

\footnotetext{
${ }^{3}$ Лео Штраус О тирании. М. 2006
} 
DOI: $10.7256 / 1811-9018.2013 .10 .9567$

При цитировании этой статьи сноска на dоі обязательна

\section{Право и политика $10(166) \cdot 2013$}

зультаты экономической экспертизы, включающей в себя выписки из соответствующих документов, к их словам было совершенно другое отношение. С другой стороны, какой современный ученый согласится принять теорию тирании и любую другую теорию, касающуюся социологии и антропологии, разработанную на основании двух свидетельств и одного текста? Разве не потребует он ссылки на более обширную выборку? Разве не придерется к явному отсутствию алгоритмов подсчета данных?

Постановка вопроса, приемы и самый их дух тестов Кожева и Штрауса неявно отсылают к образу ученого, вышедшего из употребления как минимум сто лет назад 4 . Речь идет о мудреце или, точнее, гении - человеке, наделенном особыми талантами к познанию. Согласно общему представлению того времени, он способен понимать больше других. Не отрицая роль таланта в науке, мы предлагаем осмотреть последние теории интеллектуального действия. Коллинз, Кун, Хабермас, отчасти Фуко ${ }^{5}$, утверждаю, что какой бы сильной не была предрасположенность к решению сложных теоретических задач, она не сможет развиться в полную силу без поддержки группы. Поддержка эта выражается не только в создании необходимой эмоциональной атмосферы, свободной от давления идеологических императивов, но и в ежедневном и ежечасном обмене идеями. Собственно, построение хорошей теории, особенно гуманитарной, до определенной степени невозможно без советов и критики со стороны и единомышленников и противников. Теория, образно выражаясь, творится сразу во многих головах. Индивидуальное творчество, когда все стадии разработки проводятся самостоятельно - нонсенс. Конечно, у этой точки зрения есть противники с весомыми аргументами, однако нельзя не признать, что тон, взятый и Штраусом и Кожевым, не укладывается в современные стандарты. Оба они всего лишь люди, и наблюдения их, несмотря на очевидные достоинства, это наблюдения людей, пусть и талантливых, пусть и информированных.

Изменив стилистику и подставив соответствующие имена, диалог Штрауса-Кожева легко представить в декорациях платоновской Академии, у письменного стола

${ }^{4}$ Catherine and Michael Zuckert The Truth about Leo Strauss. Chicago 2006 C. $120-155$

${ }^{5}$ Например: Коллинз Р. Социология философий: глобальная теория интеллектуального изменения. Новосибирск. 2002; Хабермас Ю. Моральное сознание и коммуникативное действие СПб. 2000; Кун Томас. Структура научных революций. М.2003; Фуко М. Слова и вещи. Археология гуманитарных наук. М.1977.
Светония Транквилла, при дворе Борджиа, в кулуарах парламента Веймарской республика, вообще везде, где имела место быть рефлексия о политическом ${ }^{6}$. В наше время так рассуждают о вечных вопросах, о проклятых вопросах, об этике и суждениях вкуса, но ни в коем случае не о деле. Темы, интересовавшие Декарта и Юма, разработанные ими в рамках доступного материала, со временем были переданы частным дисциплинам, естественнонаучным по большей части. В свободное плавание ушли психология, социология, антропология и многие другие. Уход этот неизменно сопровождался выхолащиванием языка. Приемы, свойственные художественной литературе, образность и нарочитая неясность изложения, служившие украшению, сменились жесткой сеткой терминов и дисциплиной логики. Известная лёгкость картезианских трактатов, посвященных душе, и недоступность для неспециалиста современных психологических исследовании свидетельствует именно об этом. Философический флёр, вполне уместный на заре Просвещения, морально устарел уже в девятнадцатом веке. Достаточно вспомнить атаку Венского кружка на тексты немецких экзистенциалистов ${ }^{7}$ и критику Адорно “жаргона подлинности”. Интересно, что философия, казалось бы, самая архаичная и самая сомнительная дисциплина, вот уже сто лет как ищет способы отказаться от метафизичности и всецело уподобиться царице наук, в то время как политология, несмотря на свой прикладной характер, наоборот, напускает туману.

Политолог двадцать первого века, в сущности, ничем не отличается от политолога начала нашей эры. Изменилась, разве что, стилистика, да и то не очень. Хорошим тоном считается темное письмо со множеством эзотерических аллюзий и коннотаций ${ }^{9}$, как будто информативными, как будто помогающими понять, на самом же деле совершенно бессмысленными и ненужными. Учитывая профессиональность авторов и их умение, когда надо, быть доступными и убедительными, не трудно предположить либо нежелание говорить, либо, что интересней, нежелание повторяться.

\footnotetext{
${ }^{6}$ Например. Leo Strauss Studies in platonic political philosophy Chicago 1983; Leo Strauss Persecution and the art of writing Chicago 1988; Leo Strauss The city and the man Chicago 1978.

${ }^{7}$ Р.Карнап Преодоление метафизики логическим анализом языка // Вестник МГУ», сер. 7 «Философия» - 1991 - № 6 - С. 11-26.

${ }^{8}$ Теодор В. Адорно Жаргон Подлинности. М. 2011.

9 Удачный анализ у Laurence Lambert Strauss recovery of esotericism// в сборнике The Cambridge companion to Leo Strausse под ред. Steven В. Smith Cambridge 2009 C. 63-93
} 
DOI: $10.7256 / 1811-9018.2013 .10 .9567$

При цитировании этой статьи сноска на доі обязательна

Правовая и политическая мысль

В первом случае, говоря о политике, они были бы вынуждены раскрыть карты, показать игру, в которой принимают участие и взять на себя риски, связанные с разглашением обстоятельств тайных сговоров и конфликтов. Нарушение “дисциплины аркана" означает исключение из властных сообществ и преследование, т.е. конец профессиональной карьеры. Когда на одних весах благополучие, не только свое, но и семьи и, возможно, близких родственников, а с другой, - призрачный шанс попасть в историю, самый тщеславный человек, одержимый желанием известности, сделает выбор в пользу молчания. Раз нельзя сказать прямо, а желание высказаться не дает покоя, остаются намёки и упражнения в стиле, достаточно безобидные для того, чтобы лишиться места, и достаточно смелые, чтобы почувствовать удовлетворение. Как правило, в результате получается еще один пересказ канонических текстов Макиавелли, Гоббса, Шмитта, Батая, демонстрирующий не столько причастность автора к конкретным событиям, сколько уровень владения языком и умение плавно обходить опасные для себя темы. Сильно огрубляя, можно сказать, что политологический трактат - намек окружающим на свое участие в повестке, о которой им известно из газет и слухов. Намек предельно общий, указующий направление без единой подробности. В итоге, вместо детального описания поступков, вместо аналитики, согласно правилам, принятым у культурологов, антропологов и психологов, читатель, специалист или профан - не важно, получает размытую картину без ссылки на оригинал. Хуже того, истинное положение дел нарочно сокрыто, причем профессионально и тщательнейшим образом.

Впрочем, за потребностью высказаться стоит не только жажда письма, вполне естественная для человека, зарабатывающего на жизнь пером и бумагой. Интеллектуал, инвестировавший свой диплом в политику, далеко не одинок. Помимо заказчиков, его окружает профессиональное сообщество, требующее репутации. Уровень контрактов, конечно, имеет значение, однако, сам по себе, без продуманной тактики самозащиты, он провоцирует менее удачливых коллег на зависть и, далее, на агрессивные действия, выражающиеся в распространении мнения о недостаточной квалификации или полном отсутствии таковой. На первый взгляд, разумней было бы их игнорировать, особенно, если карьера складывается удачно. Однако, в долгосрочной перспективе изоляция означает отсутствие страховки на случай внезапного ухудшения, весьма, кстати, вероятного, учитывая перманентную нестабильность, царящую в политических сферах. Рано или поздно, по той или иной причине, случайно или преднамеренно политолог окажется в ситуации поиска работы и доброе имя среди коллег - то немногое, что действительно сможет ему помочь не уйти на покой раньше, чем он того заслуживает. Заказчик, осуществляя поиск исполнителя, принимает в расчет с одной стороны, рекомендации равных себе, т.е. таких же заказчиков, как и он сам, с другой - рекомендации сообщества исполнителей. Первый вариант маловероятен, поскольку действительно стоящий специалист, скорей всего, уже нанят, к тому же накал противостояния между группами обычно требует своего рода присяги на верность, а это по понятным причинам серьезно затрудняет процесс перехода. Поэтому условный Макиавелли чаще всего или достается по наследству от старшего поколения или воспитывается, что опять же, многократно умножает проблемы, связанные со сменой сеньора, делая их практически неразрешимыми. Рекомендация от исполнителей, или, точнее выражаясь, рекомендация от конкурентов вещь не менее запутанная: ведь человек, готовый занять должность советника, но указывающий на другого, поступает, по меньшей мере, глупо. В его интересах, не только экономических, но и профессиональных, взять место себе. Даже если речь идет не о реальной вакансии, а о самой возможности претендовать на нее, когда она появится, было бы разумней распорядиться ей, сообразуясь с выгодой одной из неформальных групп, в которых имеешь участие. Несмотря на яростный индивидуализм, отсутствие профсоюзов и слабость клубов, интеллектуалы, при всей их показной любви к уединению и подчеркнутой отстраненности от житейских треволнений, поддерживают между собой довольно прочные связи и когда дело доходит до поиска средств к существованию, охотно пускают их в дело. На наш взгляд, репутация и причастность к определенному сообществу, распределяющему внутри себя карьерные и финансовые возможности, отличается друг от друга по значению. Известность, доброе имя, уважение словом, подлинное содержание термина «репутация», подразумевает способность выйти за границы группы или, лучше, шанс войти в любую из них. Со статусом, допустим, почетного профессора. Последний, как нам кажется, довольно точно отражает суть репутации: человек, обладающий ею в полной мере, находится до определенной степени над схваткой. Его положение в чем-то сродни положению маргинала, человека, 
DOI: $10.7256 / 1811-9018.2013 .10 .9567$

При цитировании этой статьи сноска на dоі обязательна

\section{Право и политика 10 (166) • 2013}

который сам отказался от участия в специфической интеллектуальной борьбе за место под солнцем или был из нее исключен помимо своей воли вследствие неудачно сложившихся обстоятельств. И наш почетный профессор и маргинал располагаются как будто за пределами сетей знакомств. Разница становится видна, когда тот и другой попытаются вступить в одну из них. Насколько велики шансы профессора сразу войти внутрь, не абы куда, а непосредственно в правление, настолько бесперспективны усилия маргинала. В лучшем случае он будет допущен до нижних ступеней, хотя, к сожалению для него, статистически более вероятным является полное и бесповоротное отторжение. Рынок труда постоянно переполнен наивными молодыми людьми, готовыми с жаром выполнять любую работу, невзирая на её рутинность и низкую оплату, в надежде снискать расположение. В этой ситуации маргинал, уже имеющий опыт и знающий, пусть и приблизительно, что к чему, не только не желателен, но и опасен. Уже сама его манера общения способна сократить до нуля время, необходимое новому призыву для того, чтобы окончательно увидеть истинное положение вещей и здраво оценить перспективы продолжения карьеры на выбранном поприще. Следовательно, признания от заказчика мало; необходимо признание от конкурентов, иначе заказчики, столкнувшись с негативными оценками сделанного выбора, в конце концов, вынуждены будут изменить решение и найти себе более именитого эксперта. Сфера политического не знает жесткого разделения на игроков и тренеров. Советник, как бы он ни старался уйти в тень и переодеться в рясу серого кардинала, участвует в повестке наравне со своим подопечным. Иногда достаточно одного присутствия, без исполнения служебных обязанностей, чтобы чаша весов качнулась в нужную сторону. Отсюда настойчивое внимание к градусу влияния, в некоторых случаях более пристальное, чем к списку удачно проведенных компаний. Связь с последним, разумеется, есть, но не жесткая. В пределе, хорошая репутация способно сгладить урон, нанесенный поражением.

Общество негласно требует иннаугурационной работы, на основании которой оно могло бы оценить автора как автора. Имеется в виду тест, призванный засвидетельствовать его “реальный” интеллектуальный уровень. Что это такое, понять не трудно. Речь идет об атаке на распространенный среди интеллектуалов упрек по отношению к более успешному коллеге, суть которого заключается в том, что его успех основывается не на профессиональных компетенциях, а на причастности к той или иной сети знакомств. Упрек этот весьма опасен, поскольку сводит на нет заслуги, представляя их как игру случая, блеф или закономерный результат усвоенного габитуса. Практически это означает написание работы в жанре политического трактата на одну из признанных тем, в которой автор обязан показать умение владеть словом и прозрачно намекнуть на свой опыт причастности к серьезным политическим процессам. Обязательно показать навык теоретизирования, желательно на критическом разборе двух-трех популярных концепций, достаточно изощренных и достаточно известных. По сути, речь идет о стандартном квалификационном сочинении, принятом в высших учебных заведениях, с тем лишь отличием, что в качестве судей выступают конкуренты, а вместо научной степени, если можно так выразиться, дается репутация. Очевидно, что при таком раскладе положительный отзыв практически невозможен, поскольку оценщики кровно заинтересованы в уничтожении противника с одной стороны и, одновременно, в реабилитации собственных портфолио. Поэтому репутационная работа пишется в самом начале, задолго до того, как условный тиран обратит внимание ${ }^{10}$. Благосклонное внимание цеха, скорей всего, обусловлено тем, что они пока не видят соперника, а если и подозревает, то не настолько сильно, чтобы пройтись по его тезисам с достаточной степенью жесткости. Нарушение этого правила в большинстве известных нам случаев приводит к результатам, о которых мы уже говорили выше. Исключения могут быть связаны с тем редким случаем, когда интеллектуалу удается разменять статус советчика на статус управленца и отстраниться от своего прошлого на расстояние, достаточное для того, чтобы бывшие коллеги перестали признавать его в качестве своего и начали относиться к нему как к потенциальному работодателю. Тогда теории, написанные новым сувереном, несмотря на возможную их научную ценность, автоматически маркируются как парадные, т.е. лишенные другого содержания, помимо церемониального. С ними никто не будет спорить всерьез, поскольку формат общения c, условно говоря, управленцем исключает или, по крайней мере, серьезно ограничивает остроту вопросов. Правило, согласно которому ничто не угрожает жизни и здоровью собеседников вне зависимости от

\footnotetext{
${ }^{10}$ Например Leo Strauss The early writings (1921 - 1932) New York 2002 и Александр Кожев Введение в чтение Гегеля М. 2003.
} 
DOI: $10.7256 / 1811-9018.2013 .10 .9567$

При цитировании этой статьи сноска на доі обязательна

Правовая и политическая мысль

исхода спора - всего лишь правило, к тому же политический деятель не может позволить себе роскошь свободного общения с открытым финалом. Обладая властью, он всегда является объектом пристального внимания со стороны подчиненных, союзников и, в особенности, противников из чего следует совершенная неискренность речи. Наивный информант социальной антропологии, просто и безыскусно рассказывающий ученому о себе, прямо противоположен политику, чьи слова - всегда маневр. Он не столько описывает реальность, сколько на нее воздействует; если мы говорим о действительно мощном персонаже, его слова и есть реальность. Удавшийся политик оперирует словами как действиями, а отсюда следует изменение их функции: слова не описывают, не отражают и не понимают, а принуждают; они инструмент насилия, инструмент воздействия, сопоставимый по силе с обычным оружием.

Другими словами, оказание услуг советника тирану нуждается в символической легитимации со стороны цеха для чего и пишется работа. Разумеется, требование размыто и редко проговаривается вслух, но, тем не менее, участники игры рано или поздно с ним сталкиваются. Проблема та же: необходимо высказаться о политике, но так, чтобы тебя из нее не прогнали прочь, во-первых, люди, на которых ты работаешь, во-вторых, конкуренты. Если наше предположение соответствует действительности, средний трактат о проблемах власти представляет собой сеть из нарочных замалчиваний и оговорок, решающих де указанные задачи.

Из практики обязательной литературной зашифровки текста следует особый тип учености, атавистичный до нельзя. Сформировавшийся на подобных текстах специалист говорит не о реальности, как хотелось бы, а о тайне, мистике и чуть ли не об алхимии. Если это человек, причастный к политической жизни в роли, допустим, эксперта, его речь - двойной ход, позволяющий, одновременно, и сказать и не сболтнуть лишнего. Главное, он знает истинную цену трактата: она равна нулю. А вот если стать на место Макиавелли не получилось и опыт политики не сильно отличается от профанного, велик соблазн принять абстракцию за подлинник. Политологический текст, наполненный эзотерической лирикой и известного сорта пафосом, после которых не остается никакого иного содержания, кроме, может быть, торжественного настроения, сродни богослужебному, - вещь, к сожалению, обычная. Ничего дурного тут нет. В недавнем прошлом наука состояла сплошь из текстов, написанных на подобии трактатов о фило- софском камне. Античная традиция поэмы о природе, когда знания упаковывались в сложные стихотворные формы - хороший пример. Проблема в том, что во всех остальных областях, за исключением науки о власти, время ушло вперед и от экзальтации прошлого ничего не осталось. Политологи, кажется, последние, кто еще верит в возможность обратить камень в золото. Вроде бы уже есть соответствующая специальность со всем необходимым методологическим инструментарием, критическим запалом и исследовательским программами, но нужный продукт не возникает.

Феномен методологической и, как следствие, содержательной отсталости политологии в чем-то напоминает ситуацию вокруг проблемы сознания. Физиологам до сих пор не удалось найти правильного подхода и задачу пока решают философы, занимающиеся, как им и положено, обобщениями, феноменологией и мысленными экспериментами. Видимо, политическое обладает сопоставимой степенью сложности, и указанные нами недостатки, пока не устранимы, как неустранимы до поры до времени философы из рассуждений о природе сознательных состояний.

\section{Библиография:}

1. Catherine and Michael Zuckert. The Truth about Leo Strauss. The University of Chicago Press Chicago 2006.

2. Carnap R, Reichenbach H. Erkenntnis / Leipzig, 19301931. Bd. 1. Перевод выполнен А. В. Кезиным и впервые опубликован в журнале «Вестник МГУ», cep. 7 «Философия», № 6, 1993, с. 11-26.

3. Leo Strauss Persecution and the art of writing. The University of Chicago Press, Chicago 1988.

4. Leo Strauss Studies in platonic political philosophy. The University of Chicago Press, Chicago 1983.

5. Leo Strauss The city and the man. The University of Chicago Press, Chicago 1978.

6. Leo Strauss The early writings (1921-1932) Translated and edited by Michael Zank. State University of New York Press, New York, 2002.

7. Steven B. Smith Reading Leo Strauss: politics, philosophy Judaism. The University of Chicago Press, Chicago, 2006.

8. Адорно Теодор В. Жаргон подлинности. О немецкой идеологии. Пер.: Е. В. Борисов М.: «Канон+» РООИ «Реабилитация», 2011.-191 с. 
DOI: $10.7256 / 1811-9018.2013 .10 .9567$

При цитировании этой статьи сноска на доі обязательна

\section{Право и политика 10 (166) • 2013}

9. Кожев Александр. Введение в чтение Гегеля и другие работы / Пер. с фр. - М.: Наука, 2003.

10. Коллинз Рэндалл. Социология философий. Глобальная теория интеллектуального изменения / Пер. с нем. Н.С.Розова-Новосибирск: Сибирский хронограф, 2002.

11. Кун Томас. Структура научных революций / Пер. с англ. И. Налетов - М.: АСТ, 2009.

12. Дэниел Хаусман. Философия экономики. Антология. Перевод с английского Н. Автономовой, И. Болдырева, Ю. Каптуревского, П. Клюкина, М. Левиной, А. Фофонова, М. Шерстнева, М.: Изд. Института Гайдара, 2012. - 520 с.

13. Фуко Мишель. Слова и вещи. Археология гуманитарных наук / Пер. с фр. - М.: А-cad, 2004.

14. Хабермас Юрген. Моральное сознание и коммуникативное действие / Пер. с нем. С . Шачин, Д. Скляднев. Под ред. Борис Марков - М.: Наука, 2006.

15. Штраус Лео О тирании / Пер. с англ. И древнегреч. А.А. Россиуса, пер. с франц. А.М. Руткевича. СПб.: Изд-во С.Петерб. ун-та, 2006. - 328 с.

\section{References (transliteration):}

1. Catherine and Michael Zuckert. The Truth about Leo Strauss. The University of Chicago Press Chicago 2006.

2. Carnap R, Reichenbach H. Erkenntnis / Leipzig, 1930-1931. Bd. 1. Perevod vypolnen A. V. Kezinym i vpervye opublikovan v zhurnale «Vestnik MGU», ser. 7 «Filosofiya», № 6, 1993, s. 11-26.

3. Leo Strauss Persecution and the art of writing. The University of Chicago Press, Chicago 1988.

4. Leo Strauss Studies in platonic political philosophy. The University of Chicago Press, Chicago 1983.

5. Leo Strauss The city and the man. The University of Chicago Press, Chicago 1978.

6. Leo Strauss The early writings ( 1921-1932) Translated and edited by Michael Zank. State University of New York Press, New York, 2002.

7. Steven B. Smith Reading Leo Strauss: politics, philosophy Judaism. The University of Chicago Press, Chicago, 2006.

8. Adorno Teodor V. Zhargon podlinnosti. O nemetskoi ideologii. Per.: E. V. Borisov M.: «Kanon+» ROOI «Reabilitatsiya», 2011.-191 s.

9. Kozhev Aleksandr. Vvedenie v chtenie Gegelya i drugie raboty / Per. s fr. - M.: Nauka, 2003.

10. Kollinz Rendall. Sotsiologiya filosofii. Global'naya teoriya intellektual'nogo izmeneniya / Per. s nem. N.S.Rozova-Novosibirsk: Sibirskii khronograf, 2002.

11. Kun Tomas. Struktura nauchnykh revolyutsii / Per. s angl. I. Naletov - M.: AST, 2009.

12. Deniel Khausman. Filosofiya ekonomiki. Antologiya. Perevod s angliiskogo N. Avtonomovoi, I. Boldyreva, Yu. Kapturevskogo, P. Klyukina, M. Levinoi, A. Fofonova, M. Sherstneva, M.: Izd. Instituta Gaidara, 2012. - $520 \mathrm{~s}$.

13. Fuko Mishel'. Slova i veshchi. Arkheologiya gumanitarnykh nauk / Per. s fr. - M.: A-cad, 2004.

14. Khabermas Yurgen. Moral'noe soznanie i kommunikativnoe deistvie / Per. s nem. S . Shachin, D. Sklyadnev. Pod red. Boris Markov - M.: Nauka, 2006.

15. Shtraus Leo O tiranii / Per. s angl. I drevnegrech. A.A. Rossiusa, per. s frants. A.M. Rutkevicha. - SPb.: Izd-vo S.Peterb. un-ta, 2006. - 328 s.

\section{4}

